\title{
МОДЕЛЬ РАСПРЕДЕЛЕНИЯ ОГРАНИЧЕНИЙ МЕЖДУ ПОТРЕБИТЕЛЯМИ ПРИ ДЕФИЦИТЕ ЭФФЕКТИВНЫХ топлив
}

M. MOTUS, K. JAANIMÃGI. EFEKTIIVSETE KOTUSTE TARBIMISPIIRANGUTE JAOTUSE MUDEL M. MOTUS, K. JAANIMÃGI. A MODEL FOR DISTRIBUTING BETWEEN CONSUMERS IN CASE OF EFFECTIVE FUEL DEFICIT

\author{
(Представил Н. Эпик)
}

Проблема оптимального управления процессами топливоснабжения возникает в энергетике из-за отсутствия слаженности в системах производства, потребления и снабжения. Режимы топливопотребления зависят от метеорологических условий, изменения производственных планов потребителей и производителей топлива, от аварийных ситуаций и т. д. Для обеспечения надежного топливоснабжения создаются запасы топлива, принимаются меры, направленные на повышение бесперебойной транспортировки топлива ['] и т. д.

Совершенствованию управления топливоснабжением способствует разработка методов оперативного управления в случае возникновения локального дефицита отдельных видов топлива. Разработка таких методов связана с созданием банка данных и определением целей управления. При текущем управлении в случае возникновения дефицита необходимо учитывать взаимозаменяемость различных видов топлива, величину ущерба от вводимых ограничений, технические, социальные и экономические факторы.

Математнческая модель распределения ограничений между потребителями при дефиците топлива имеет вид

$$
\begin{aligned}
& \sum_{l=1}^{m} \sum_{i=1}^{n} \eta_{i l} x_{i l} \rightarrow \max \\
& \sum_{l=1}^{m} \sum_{i=1}^{n} c_{2 i l}\left(x_{i l}^{\max }-x_{i l}\right) \rightarrow \min , \\
& \sum_{l=1}^{m} \sum_{i=1}^{n}\left(1 / c_{3 i l}\right) \cdot\left(x_{i l}^{\max }-x_{i l}\right) \rightarrow \min \\
& \sum_{l=1}^{m} \sum_{i=1}^{n} c_{5 i l} /\left(x_{i l} / x_{i l}^{\max }\right) \rightarrow \min
\end{aligned}
$$




$$
\begin{aligned}
& \sum_{l=1}^{m} \sum_{i=1}^{n} c_{6 i l} /\left(x_{i l} / x_{\mid i l}^{\max }\right) \rightarrow \min , \\
& \sum_{l=1}^{m} \sum_{i=1}^{n} c_{7 i l} \cdot\left(x_{i l} / x_{i l}^{\max }\right) \rightarrow \min , \\
& \sum_{l=1}^{m} x_{i l}=x_{i}, \\
& \sum_{i=1}^{n} \eta_{i l} x_{i l} \leqslant Q_{l},
\end{aligned}
$$

где $\eta_{i l}-$ кпд $i$-го вида топлива у $l$-го потребителя; $Q_{l}-$ полезное потребление топлива $l$-м потребителем, $T y . T . ; x_{i l}, x_{i l}$ max - количество $i$-го топлива, выделяемое и необходимое $l$-му потребителю соответственно, т $y . T . ; x_{i}-$ количество $i$-го вида топлива, $т$ y.T.; $c_{2 i l}-$ удельный ущерб от ограничения $i$-го топлива у $l$-го потребителя, pyб/T y.T.; $c_{3 i l}$ - топливообеспеченность персонала, т y.т./чел; $c_{5 i l}, c_{6 i l}$ - часы использования $x_{i l} \max l$-м потребителем в сутки и установленной мощности в год; $c_{7 i l}$ - размер запаса $i$-го топлива у $l$-го потребителя, $т$ y.t.; $n$ - количество эффективных видов топлива; $m$ - количество потребителей; $x_{i l}{ }^{\max }$ находится из решения задачи оптимизации ТЭБ района $\left[{ }^{2}\right]$.

Вместо функционала (1) можно рассматривать функционал $\sum_{l=1}^{m} \sum_{i=1}^{n} c_{1 i l} x_{i l}$, где $c_{1 i l}-$ удельная валовая продукция $l$-го потребителя при использовании $i$-го вида топлива, руб/т y.т.

Для решения задачи (1)-(8) применимы методы из $\left[{ }^{3}\right]$. Эта задача решается для одного района, скажем, снабжаемого с одной нефтебазы. На основе решения этой задачи строятся характеристики, представляющие собой зависимости функционала эффективности задачи (1)-(6), получаемого в процессе ее решения $\left[{ }^{4}\right]$, от количеств топлива. Построение таких характеристик позволяет осуществлять распределение ограничений между районами на основе решения задачи

$$
\begin{gathered}
z_{j} \rightarrow \min , \quad j=1,2, \ldots, J, \\
\sum_{j=1}^{J} x_{i j}=x_{i}, \\
x_{i j} \leqslant x_{i j}^{\max },
\end{gathered}
$$

где $J$ - количество районов, $z_{j}-$ соответствующие характеристики.

\section{ЛИТЕРАТУР А}

1. Козырев Б. А., Альтшуль А. А., Мацкевич В. И., В кн.: Системы энергетики - тенденции развития и методы управления, 4, Иркутск, «Наука», 1980 ; c. $66-74$.

2. В а й к Л. Э., Принщипы и методы взаимосвязанной оптимизащии топливно-энергетического хозяйства районов и страны, Автореф. докт, дис., М., 1976.

3. Д ехтя яенко В. А., С в о ятыцкий Д. А., Препринт 76-30 Ин-та кибернетики АН УССР, Киев, 1976.

4. Я а н п яги К. Э., Методы оптимального распределения ограниченных топливноэнергетических ресурсов между потребителями, Автореф. канд. дис., Л., 1980.

Ннститут термофизики и электрофизики Академии наук Эстонской ССР
Поступила в редакцию $3 / \mathrm{X} 1980$ 